\title{
A lesson on induction of hypothermia and measurement of efficacy
}

\author{
Bridget A Harris $^{1}$ and Peter JD Andrews ${ }^{2^{*}}$ \\ See related research by Poli et al., http://ccforum.com/content/18/5/582
}

\begin{abstract}
Brain injuries caused by stroke are common and costly in human and resource terms. The result of stroke is a cascade of molecular and physiological derangement, cell death, damage and inflammation in the brain. This, together with infection, if present, commonly results in patients having an increased temperature, which is associated with worse outcome. The usual clinical goal in stroke is therefore to reduce temperature to normal, or below normal (hypothermia) to reduce swelling if brain pressure is increased. However, research evidence does not yet conclusively show whether or not cooling patients after stroke improves their longer-term outcome (reduces death and disability). It is possible that complications of cooling outweigh the benefits. Cooling therapy may reduce damage and potentially improve outcome, and head cooling targets the site of injury and may have fewer side effects than systemic cooling, but the evidence base is unclear.
\end{abstract}

The recent study by Poli and colleagues [1] is part of a suite of iCOOL studies in ischaemic and haemorrhagic stroke, conducted at Heidelberg and linked to EuroHYP-1 (European multicentre, randomised, phase III clinical trial of therapeutic hypothermia plus best medical treatment versus best medical treatment alone for acute ischaemic stroke [2]). Altogether the studies tested four different methods of inducing hypothermia for speed of brain cooling, feasibility and safety. Rhinochill and the Sovika head and neck cooling device [1] and cold infusions compared with Rhinochill (Rhinochill, Wallisellen, Switzerland, EU) (iCOOL 1 NCT01573117 [1]), EMCOOLS Flex.Pads (EMCOOLS, Brucknerstrasse 6/7a, 1040 Vienna, Austria)

\footnotetext{
* Correspondence: p.andrews@ed.ac.uk

${ }^{2}$ Department of Anaesthesia and Critical Care, University of Edinburgh and

NHS Lothian, Western General Hospital, Edinburgh EH4 2XU, UK

Full list of author information is available at the end of the article
}

(iCOOL 2 NCT01584167) and EMCOOLS Brain.Pad (EMCOOLS, Brucknerstrasse 6/7a, 1040 Vienna, Austria) (iCOOL 3 NCT01584180). The methods of inducing hypothermia that are now included in the protocol for EuroHYP-1 are cold infusion $\left(20 \mathrm{ml} / \mathrm{kg} 4^{\circ} \mathrm{C}\right.$ isotonic sodium chloride or Ringer's lactate over 30 to 60 minutes) with optional use of EMCOOLs Brain.Pad [3].

There has been an ongoing quest for methods of therapeutic cooling that reduce temperature rapidly, are portable and easily instigated and/or have the least side effects. Cold infusion as a method of inducing cooling has most often been studied in cardiac arrest but is currently being used in clinical trials of therapeutic hypothermia in stroke (EuroHYP-1 [3]) and traumatic brain injury (Eurotherm3235Trial [4] and POLAR (NCT00987688)). The attraction is that it is a relatively low-tech, readily available, portable method, requiring only a means of keeping the infusion fluid at $4^{\circ} \mathrm{C}$. Direct brain cooling has a long history but there are few randomised controlled trials and most are of low quality [5]. One of the attractions has been the assumption that direct brain cooling has fewer side effects than systemic cooling but this has not been established [5]. Various methods of nasopharyngeal cooling have been reported in the literature [5], including Rhinochill and nasal [6] and pharyngeal balloons [7]. Rhinochill has been studied most (for example, [8]) and there is very limited human data on the pharyngeal balloon device [7] or the pharyngeal cooling system of Takeda. Springborg and colleagues [6] report the use of QuickCool nasal balloons in a mixed group of hyperthermic brain-injured patients. Temperature was measured in the oesophagus, bladder and (in some patients) intracranially. The goal of normothermia was not reliably achieved. As with Poli and colleagues [1], this research raises questions about bladder temperature as a proxy for intracranial temperature.

Perfluorocarbons are costly and their use in Rhinochill has been questioned on environmental grounds [9].
Ciomed Central

(c) 2014 Harris and Andrews; licensee BioMed Central Ltd. The licensee has exclusive rights to distribute this article, in any medium, for 12 months following its publication. After this time, the article is available under the terms of the Creative Commons Attribution License (http://creativecommons.org/licenses/by/4.0), which permits unrestricted use, distribution, and reproduction in any medium, provided the original work is properly credited. The Creative Commons Public Domain Dedication waiver (http://creativecommons.org/publicdomain/zero/1.0/) applies to the data made available in this article, unless otherwise stated. 
Although in the overall context of medical interventions Rhinochill may not have major environmental impact, this nevertheless warrants consideration. Use of Rhinochill requires patients to be intubated and is contraindicated with base of skull fracture, which limits its use in traumatic brain injury.

Recently another method of nasopharyngeal cooling has been reported by Fontaine and colleagues [10], with experimental evidence and a human case report. This method uses adiabatic expansion of gas pressure; $1 \mathrm{~L}$ compressed carbon dioxide delivered via a nasal cannula. Temperature is reduced because as the gas expands the pressure reduction transfers energy as work (very rapidly) and not as heat, although in practice there is some heat transfer as insulation is not perfect. Carbon dioxide is of course also a greenhouse gas and using it in this way requires patients to be intubated. Compressed air and oxygen were tested experimentally as alternatives and found to remove considerably less heat than carbon dioxide, but in vivo temperature differences were not significant. In their study, Poli and colleagues [1] show very nicely how different sites of temperature measurement reflect temperature change differently using intravenous and nasopharyngeal cooling. Where intracranial temperature is the key temperature of interest, as it arguably is in stroke and traumatic brain injury, their data show the importance of measuring this. As yet, however, there does not seem to be much appetite for targeting therapeutic cooling to intracranial temperature - invasive measurement is not clinically warranted in less severe stroke and traumatic brain injury - and core body temperature is the usual feedback parameter. In this case Poli and colleagues' data [1] strongly suggest oesophageal temperature is the best proxy for intracranial temperature. One difficulty with this site of measurement is that with longerterm cooling, if drugs are given nasogastrically, this will affect the temperature readings [11]. Another is having to site both a nasogastric tube and an oesophageal temperature probe with attendant increased risk of sinusitis and abrasions. There have been moves to produce a nasogastric tube suitable for feeding/drug instillation, aspiration and temperature measurement but to our knowledge such a potentially useful device is not yet in commercial production.

The authors are to be congratulated on their comprehensive measurement of temperature reduction efficacy and clear presentation of data measured at multiple sites. The challenge is to move from evidence of efficacy (temperature reduction) to evidence of effectiveness and improved patient outcomes.

\section{Author details}

"NHS Lothian and University of Edinburgh, Critical Care Unit, Western General Hospital, Edinburgh EH4 2XU, UK. ${ }^{2}$ Department of Anaesthesia and Critical Care, University of Edinburgh and NHS Lothian, Western General Hospital, Edinburgh EH4 2XU, UK.

Published online: 22 December 2014

\section{References}

1. Poli S, Purrucker J, Priglinger M, Ebner M, Sykora M, Diedler J, Bulut C, Popp E, Rupp A, Hametner C: Rapid Induction of COOLing in Stroke Patients (iCOOL1): a randomised pilot study comparing cold infusions with nasopharyngeal cooling. Crit Care 2014, 18:582.

2. EuroHYP: Small and Medium Sized Enterprises (SMEs) [http://www.eurohyp.org/SME.html]

3. van der Worp HB, Macleod MR, Bath PM, Demotes J, Durand-Zaleski I, Gebhardt B, Gluud C, Kollmar R, Krieger DW, Lees KR, Molina C, Montaner J, Roine RO, Petersson J, Staykov D, Szabo I, Wardlaw JM, Schwab S, EuroHYP-1 investigators: EuroHYP-1: European multicenter, randomized, phase III clinical trial of therapeutic hypothermia plus best medical treatment vs. best medical treatment alone for acute ischemic stroke. Int J Stroke 2014, 9:642-645.

4. Andrews PJ, Sinclair HL, Battison CG, Polderman KH, Citerio G, Mascia L, Harris BA, Murray GD, Stocchetti N, Menon DK, Shakur H, De Backer D, Eurotherm3235Trial collaborators: European Society of Intensive Care Medicine study of therapeutic hypothermia (32-35degrees $\mathrm{C}$ ) for intracranial pressure reduction after traumatic brain injury (the Eurotherm3235Trial). Trials 2011, 12:8.

5. Harris B, Andrews P, Murray G, Forbes J, Moseley O: Systematic review of head cooling in adults after traumatic brain injury and stroke. Health Technol Assess 2012, 16:1-175.

6. Springborg JB, Springborg KK, Romner B: First clinical experience with intranasal cooling for hyperthermia in brain-injured patients. Neurocrit Care 2013, 18:400-405.

7. Takeda Y, Hashimoto H, Fumoto K, Danura T, Naito H, Morimoto N, Katayama H, Fushimi S, Matsukawa A, Ohtsuka A, Morita K: Effects of pharyngeal cooling on brain temperature in primates and humans: a study for proof of principle. Anesthesiology 2012, 117:117-125.

8. Castrén M, Nordberg P, Svensson L, Taccone F, Vincent IL, Desruelles D, Eichwede F, Mols P, Schwab T, Vergnion M, Storm C, Pesenti A, Pachl J, Guérisse F, Elste T, Roessler M, Fritz H, Durnez P, Busch HJ, Inderbitzen B, Barbut D: Intra-arrest transnasal evaporative cooling: a randomized, prehospital, multicenter study (PRINCE: Pre-ROSC IntraNasal Cooling Effectiveness). Circulation 2010, 122:729-736

9. Gupta D, Kable T, Orlewicz M: RhinoChill: do we need per-fluorocarbons? Resuscitation 2011, 82:784.

10. Fontaine G, Lapostolle F, Didon JP, Schmid JJ, Jouven X, Chachques JC: New methods to induce localized brain and general hypothermia. In Resuscitation. Edited by Gullo A, Ristagno G. Milan: Springer; 2014:189-199.

11. Harris BA, Andrews PJD, Murray GD: Enhanced upper respiratory tract airflow and head fanning reduce brain temperature in brain-injured, mechanically ventilated patients: a randomized, crossover, factorial trial. Br J Anaesth 2007, 98:93-99.

doi:10.1186/s13054-014-0710-y

Cite this article as: Harris and Andrews: A lesson on induction of

hypothermia and measurement of efficacy. Critical Care 2014 18:710. 